\title{
¿Por qué son felices los dermatólogos?
}

\author{
José Luis Sandoval-Gutiérrez
}

Secretaría de Salud, Instituto Nacional de Enfermedades Respiratorias "Ismael Cosío Villegas", Servicio de Neumología, Ciudad de México, México

Fierro-Arias et al. ${ }^{1}$ reportan un trabajo interesante sobre la satisfacción laboral y la felicidad en los profesionales de su especialidad.

La definición de felicidad, según el diccionario de la Real Academia Española, señala: ${ }^{2}$

Del lat. felicitas, -ātis.

1. f. Estado de grata satisfacción espiritual y física.

2. f. Persona, situación, objeto o conjunto de ellos que contribuyen a hacer feliz.

3. f. Ausencia de inconvenientes o tropiezos.

En cualquier actividad profesional es importante el grado de satisfacción que esta pueda producir en el sujeto, como condicionante para lograr un equilibro laboral-personal.

El medio en el que se desarrolla una vocación puede provocar que el gusto inicial con el que se decidió tomar este camino se vuelva hostil, pudiéndose dudar de la entrega, cariño e identificación que al principio se tenía.

Los acontecimientos recientes del gremio médico mexicano enfatizan la necesidad de una mejora en la situación administrativa, estructural, salarial y de procedimientos para un total desempeño médico en un ambiente profesional y grato. ${ }^{3,4}$

Si algún extranjero lee el manuscrito de los autores mencionados, encontrará que al parecer México ofrece un campo inmejorable para el desarrollo de la dermatología, ya que $93 \%$ de los encuestados se manifestó muy satisfecho con su especialidad y $98.6 \%$ volvería a escogerla, con un promedio 16 años de ejercicio.

Otros campos de la medicina (como la oncología, terapia intensiva, cirugía general o urgencias, entre otros) han mostrado características que los definen, pero generalmente no es un alto grado de satisfacción y felicidad, sobre todo los primeros años de formación.
Alguien podría preguntar, ¿por qué un médico opta por esas especialidades? Otra persona podría responder que "por vocación", la cual en el diccionario se define de la siguiente forma: ${ }^{5}$

Del lat. vocatio, -ōnis 'acción de llamar'.

1. f. Inspiración con que Dios llama a algún estado, especialmente al de religión.

2. f. advocación.

3. f. Inclinación a un estado, una profesión o una carrera.

4. f. desus. Convocación, llamamiento.

Por lo cual, alguien puede estar realizando una actividad por la enorme necesidad cubrir una vocación, sin necesariamente llegar a una satisfacción o felicidad completa, aunque es deseable que vocación-satisfacción-felicidad se encuentren alineadas y estén cercanas a $100 \%$.

Las nuevas generaciones de educandos, denominados mileniales, ${ }^{6}$ parecen más interesadas en lo que les produce satisfacción inmediata, que consideran a veces mal llamar "felicidad", dejando en segundo plano la vocación real, siendo esta ultima una condición necesaria para el desempeño óptimo de la medicina.

El estudio mencionado señala $72.6 \%$ de mujeres. ¿Acaso las mujeres son más optimistas?7 Describe los centros nacionales de estudios de donde egresaron los especialistas, pero no señala si se encuentran laborando en instituciones públicas, privadas o ambas.

En México es necesario hacer estudios que evalúen las distintas especialidades, ya que cada una tiene condicionantes y necesidades especiales.

El gremio necesita ser atendido en esta necesidad psicológica, ya que como un periodista alguna vez dijo:

Todos necesitaremos en la vida a un médico, así que entre mejor los tratemos, mejor nos atenderán.
Gac Med Mex. 2018;154:497-498 


\section{Bibliografía}

1. Fierro-Arias L, Simón-Díaz P, Ponce-Olivera RM, Arenas-Guzmán R Estudio sobre la satisfacción laboral y la felicidad en médicos dermatólogos. Gac Med Mex. 2018;154:26-35.

2. Real Academia Española. [Sitio web]. Felicidad. Disponible en: http://dle rae.es/?id=Hj4JtKkmn

3. Pérez-Méndez LA. Liberan a médico acusado de muerte del niño Edward en Oaxaca. Excélsior. 2018 Abr 13. Disponible en: https://www.excelsior com.mx/nacional/liberan-a-medico-acusado-de-muerte-del-nino-edward-en-oaxaca/1232189
4. Noticias, voz e imagen de Oaxaca. [En línea]. Ceden jueces y magistrados ante marcha de médicos en Oaxaca: familiares de Edward. [Consultado 2018 Abr 14]. Disponible en http://www.nvinoticias.com/ nota/89545/ceden-jueces-y-magistrados-ante-marcha-de-medicos-en-oaxaca

5. Real Academia Española. [En línea]. Vocación. [Consultado 2018 Abr 16]. Disponible en: http://dle.rae.es/?id=bzINevX

6. Waljee JF, Chopra V, Saint S. Mentoring Millennials. JAMA 2018;319:1547-1548.

7. Mariano Osorio. [Sitio web]. Las mujeres optimistas viven más. [Consultado 2018 Abr 17]. Disponible en: https://marianoosorio.com/blogs/noticias-que-te-hacen-bien/las-mujeres-optimistas-viven-mas 